\title{
Problems of cognitive distortions in cross- cultural communication when using automatic translation in the Russian Chinese dialogue
}

\author{
Abdusalamu Nijiati ${ }^{1 *}$, Irina Karabulatova ${ }^{1}$, Yuan $\operatorname{Lin}^{1}$, and Fatima Sautieva ${ }^{2}$ \\ ${ }^{1}$ RUDN University, 6 Miklukho- Maklaya St, Moscow, 117198, Russian Federation \\ ${ }^{2}$ Ingush State University, 7, Zyazikov Ave, 386001, Republic of Ingushetia, Magas, Russian \\ Federation
}

\begin{abstract}
The article is aimed at analyzing cognitive distortions in crosscultural communication when using automatic translation from Chinese to Russian, which are presented in the Internet space. Hypothesis: cognitive impairment in cross-cultural communication when automatic ChineseRussian translation due to differences in mentality of Russian and Chinese, differential specificity of cognitive picture of the world at native speakers of languages of different structures, especially the inclusion of the components in the scope of the concept, specifics of the representation of the material with different system of graphics, the mismatches of structure of Russian and Chinese proposals, etc. A special role is played by the peculiarities of the tradition of teaching and communication in Russia and China, as well as the specifics of ethnolinguopsychology. The Chinese mentality has a priority influence on the formation of respect for traditions and following them in the written style of speech. The Chinese mentality finds Parallels with the North Caucasian mentality in using the cognitive experience of its predecessors, in following the traditions of pedagogical practice. Russian Russian and Chinese Russian specialists ' practical skills in cross-cultural communication correspond to the goals, stages, and tasks of training specialists in Russian-Chinese dialogue. The method of analysis is based on an axiological approach and synergetics, including methods of ethnopsycholinguistics, cross-cultural communication, machine learning, methods of teaching languages as foreign languages in an ethno-cultural environment with significant differences in social distance.
\end{abstract}

\section{Background}

Breakthrough technologies that are taking place in the modern world have changed the nature and quality of communication, cross-cultural communication, and foreign language teaching. In this regard, machine learning technologies have become popular, changing not only virtual, but also real communication between native speakers of different languages and cultures. We consider the problem of cognitive distortions, which inevitably arises due to the presence of ethno-cultural gaps and peculiarities of mentality on the example of Russian, Chinese and North Caucasian linguistic cultures. We recognize that before the use of information and communication technologies, understanding the specifics of China and Russia was difficult due to the specific mentality and language features.

\footnotetext{
*Corresponding author: 444826938@qq.com
} 
The use of automatic translation technologies began to develop rapidly in the practice of everyday communication and teaching foreign languages [1], while transformations in cross-cultural communication began to acquire an entropic character. The intercultural communication skills acquired during the training of Russian sinologists and Chinese Russian specialists should be in progressive accordance with the goals and objectives of the discipline "Methods of teaching a language as a foreign language".

We find that the symbiosis of various styles and sub-styles of language, including literary language as such, and technical, machine, computer, while a variety of polycode, linguocreative constructions, jargon, foreign language borrowings and slash are being introduced more and more into the practice of everyday communication.

Today, the language of automatic translation has begun to play an increasing role in everyday communication, but texts are often translated automatically, which creates potential dangers [2] for an adequate understanding of speech by the addressee [3]. In this regard, Chinese scientist Ch.Liquan considers in his work "Logic-theory of correct thinking and successful communication" (2001) misunderstandings and cognitive distortions in the context of intentional misinterpretations. Russian Russian-language photos of Chinese store signs that contain errors in the text are" viral " and we are faced with a dilemma: Is this an accidental misunderstanding or a deliberate misinterpretation in order to attract Russian customers? Often, such errors are interpreted as errors in using automatic translation from Chinese to Russian [4]. However, we, following Ch. Liquan, we believe that this is a deliberate misinterpretation, which is an example of a more advanced communication strategy than ordinary misunderstanding.

Training specialists in the field of artificial intelligence training is associated with ensuring the efficiency of human life in the era of globalization and digitalization, where it is important not just a set of factual knowledge, a thesaurus recorded by dictionaries, but also the use of predictive capabilities of neural networks to avoid so-called cognitive distortions when using machine translation of texts. This aspect is important because the use of automatic translation in everyday cross-cultural communication often leads to cognitive dissonance among communicants.

\section{Methods}

The object of our research is machine translation as a promising scientific discipline that receives justification from the positions of linguopragmatics, cognitive linguistics, ethnopsycholinguistics, machine learning, cross-cultural communication and synergetics. The subject of the research is the linguistic and pragmatic principles of using the language of cognitive distortions in the Russian and Chinese dialogue, its sign characteristics, and its functioning in the discourse of intercultural communication, including various forms.

The main research methods in this paper are the secondary method of critical literature analysis, the corpus analysis method, and the induction method. The method of critical reinterpretation of literature is focused on the analysis of previously obtained results of predecessors on cognitive distortions and deliberate non-standard interpretations, as well as on the development of their own approach to the studied material. The analysis of corpus vocabulary on cognitive distortions is extracted from free sources posted on the Internet by continuous sampling. The induction method analyzes the phenomenon of "cognitive distortion" that affects the choice of communicative roles, with an emphasis on trigger factors, using the mechanism of derivation to achieve a pragmatic effect in cross-cultural communication. 


\section{Results}

The tradition of Chinese writing dates back several millennia, so modern creativity is based on following the patterns of Chinese writing [5], which is imbued with the spirit of ancient myths and legends [6].

We believe that the modern Russian and Chinese dialogue actively uses language play with the use of laughter culture, which is generally characteristic of the latest trends in the language of mass media and advertising discourse [7]. Deliberate cognitive distortion acts as a creative communication strategy that is often found in speech communication to achieve the intended communicative effect in a dialogue. The term "cognitive distortion" was proposed and developed by psychologists A. Tversky and D. Kahneman when analyzing the impact of irrational elements in research on motivation in marketing and Economics [17]. At the same time, the concept of "cognitive distortion" is understood as a regular error in the thought process, which is contrasted with a random error caused by ignorance [ibid].

Chinese researchers rightly believe that the so-called contextual ambiguity plays an important role in the art of language communication. Chinese culture refers to the civilizations of historical memory that unites this culture with the cultures of peoples of the Caucasus and Russia as a whole [21].

V. Yang and Y. Lin, after V. Jiangping, note that the recipient intentionally uses a special context for misinterpretation of the meaning of the addresser of speech or of the author's discourse [8].

At the same time, we see that the use of automatic translation in cross-cultural communication is often associated with limitations of lexical compatibility due to ethnocultural lacunae [9]. As colleagues from different countries accurately note, each language has a specific combination of lexical means that can often not be translated literally, so machine intelligence training to improve cross-cultural communication and important aspects of translation studies remains relevant, especially in the situation of teaching Russian-Chinese dialogue $[10 ; 11 ; 12]$.

Cognitive distortions in verbal behavior are caused by the ethno-linguistic and cultural distance between the Russian and Chinese languages, complicated by significant differences in the representation of lexical meaning in writing. V. Jianping identified 4 types of ambiguous understanding and representation: 1) dictionary ambiguities, 2) phraseologically determined ambiguities, 3) grammatically determined ambiguities, and 4) contextually determined ambiguities. In addition, the scientist clarifies that there are trigger factors that can be intentionally interpreted incorrectly or ambiguously.

However, we believe that the laugh effect and attracting the attention of potential recipients from the creators of texts with cognitive distortions also has hidden negative trends that aggravate the ethno-cultural distance, actualizing the "friend/ foe" contrast, forming a distorted image of the culture of another people. Researchers identify this phenomenon as potential dangers in the text since such distortions can negatively transform the ethno-linguistic consciousness of society $[2 ; 14 ; 15]$. At the same time, the use of cognitive distortion techniques during a language game can be used as a subtle tool of soft power [19], which requires a fine command of a foreign language.

The conditions for initiating cognitive distortions as a reflection of violations of ethnolinguistic and functional development can, in our opinion, be manifested in orientation to the autistic perception of the world through the actualization of digital technologies in a globalizing world for communication not only in a foreign language, but also in the native language. In this case, we observe an ethnolinguofunctional violation of the sequence of stages in the training of intercultural communication, which can proceed as a movement of a fairy-tale push (one step forward and two steps back to phylogenetically earlier stages), 
pushing the user's personality towards pathological manifestations of the psyche, towards simplifying thought processes and developing borderline States of the psyche. This idea of human mental processes is consistent with the ideas of L. Levi-Bruhl [18] about the combination of heterogeneous historical mental formations in the consciousness of modern human.

There is no doubt that modern communication technologies with the use of machine intelligence are becoming a well-honed tool for strategic planning not only in everyday cross-cultural communication, but also at the interstate level of communication, where the Central place belongs to ensuring a high level of public security [19].

In the temporal aspect, the ethno-linguo-functional meaning of returning to the selfconsciousness of modern man, for example, various anachronisms in the form of fashion trends in clothing, views, and habits is found in the inconsistency of these manifestations with his real ethno-cultural environment. It also has a certain connection with mental disorders [20].

Cognitive distortions that occur in cross-cultural communication and the specifics of using artificial intelligence tools transform the attitude of society to members of the human team as participants in a computer game.

If we look at photos of signs published on the Internet in free access, we will see the desire of the Chinese to create motivation among potential recipients of goods and services by using laughing techniques. Tourists take photos of such signs and ads, contributing to viral advertising strategies to promote a product and / or service. For example: "supermarket of pain" (in the sense of a clinic for pain treatment), "Hard jeans" (meaning traditional cotton jeans), pharmacy " Commoner "(pharmacy of budget prices), store "Broth with cow bones "Brother and sister" (beef meat store "Brother and sister"), store "Fat people monopoly" (clothing store for fat people), "Russian oil painting" (painting store), "Sex wholesale from the factory" (sex shop), etc. [22].

Our preliminary analysis allowed us to group the main cognitive distortions encountered when using machine translation in Russian and Chinese intercultural dialogue by the following typical errors:

1. The problem of lexical compatibility in the Russo-Chinese translation. The rules for word compatibility in Russian and Chinese do not match, so the use of machine translation focused on literal meanings leads to additional distortions. The volume of possible lexical combinations in Russian and Chinese do not match. For example, the concept 文明 "understanding"," comprehension of written signs", but this hieroglyph contains in translation not only such meanings as "education", "culture", "enlightenment", but also "renewal", etc.

2. The Problem of cognitive distortions due to typological differences in the transmission of meanings based on the rules of syntax. Thus, the Chinese language puts the topic of the utterance first, and this character may not have a close semantic connection with other characters, which makes it difficult to translate. In turn, the Russian language has a strict logical relationship between the subject and the predicate.

We agree with the reasoned opinion V.V. Kolomenskaya that the main feature of Chinese signs and advertisements in Russian language is in violation of the norms of the Russian language, including cognitive distortions [23], which allowed researchers to speak about a new stage in the evolution of Russian-Chinese pidgin [24]. At the same time, the creators of such texts do not realize the importance of translation for ethnoconflictology in the context of pragmatics of texts with cognitive distortions, forming, in turn, a distorted collective portrait of the Chinese in the modern Russian language consciousness. Chinese researcher Lu Tingting emphasizes the importance of adequate translation to ensure a positive Russian-Chinese dialogue [25], which, in our opinion, is closely related to the development of ethno-psycholinguistic norms of communication in Russian-Chinese cross- 
cultural communication [26]. So, the intensity of the Russian-Chinese dialogue is achieved using a variety of communication strategies that are focused on both the traditional appeal to specialist translators and digital assistants for automatic translation, which in turn creates some problems of both linguistic and extralinguistic nature.

\section{Conclusion}

The desire for language economy, the complex structure of the mechanism for encoding and decoding information in cross-cultural communication, and the confidence in the adequate transmission of meaning in automatic machine translation into another language create quite complex problems in the situation of intensive interlanguage contacts on modeling the semantic organization of the text.

As we can see, people use a variety of strategies and tactics to achieve their communication goals, clearly illustrating the difference in the presentation of information from the perspective of Western and Eastern worldviews. At the same time, the phenomenon of cognitive distortions is not only a General psychological phenomenon, but also an active pragmatic tool for creating a communicative goal of motivation for a particular fact, event, phenomenon, service, etc.

Cognitive distortions with AI contain such deliberately distorted pragmatic functions as enhancing the laughter component, manipulating information, hiding information, accentuating irony and strategies to "keep your face", indicating orientation to the Russian market segment, avoiding conflict, finding a way out of a semantic impasse, etc.

\section{Acknowledgments}

This work was supported by the Russian Foundation for Basic Research, grant No. 17-0400607-OGN.

This paper was financially supported by the Russian Foundation for Basic Research, grant No. 20-012-22046

\section{References}

1. N. G. Valeeva, E.B. Pavlova, Yu. L. Zakirova M-learning in teaching ESP: case study of ecology students. European Journal of Contemporary Education, 8(3), 920-930 (2019)

2. I.S. Karabulatova, K. V. Vorontsov Digital linguistic migratology and monitoring of potentially dangerous texts about migration. Migration bridges in Eurasia: new approaches to the formation of migration policy in the interests of sustainable development. Materials of the XI International scientific and practical forum. Edited by S. V. Ryazantsev, M. N. Khramova, 189-204 (2020)

3. A. A. Atabekova Linguistic design of WEB pages (comparative analysis of the language design of English-and Russian-language WEB pages) (2003)

4. O. V. Dubkova, Lin Mei Cognitive bases of logical violations in the written speech of Chinese Russian specialists. Communication research, 3 (5), 129-136 (2015) 
5. Nai Wan History of Chinese characters in Russian and Chinese. M: Chance, 191 (2017) (in Russ.)

6. Ma Zhen Myths and legends of China, Moscow: Chance, 143 (2020) (in Russ.)

7. S. V. Ilyasova, L. P. Amiri The language of media and advertising: the game as a norm and as an anomaly. M.: Flinta: Nauka, 328 (2018) (in Russ.)

8. Wang Yan Consituation in Russian colloquial speech. Modern Humanities research. 2 (21), 141-148 (2008)

9. I. S. Karabulatova (1999). The Russian language in the Russian Chinese border area as a core of the common linguistic base of contactee peoples. Migration processes in the Asia-Pacific region: history, modernity, interaction and regulation practices: proceedings of the international scientific and practical conference, November 10-12, 2015 Vladivostok: DFU, 219-222 (2015) (in Russ.)

10. M. Dascal Introduction: Some questions about misunderstanding. Journal of pragmatics, (31), 68 (1998)

11. E. N. Luchinskaya, I. S. Karabulatova, V. I. Tkhorik, V. V. Zelenskaya, S. A. Golubtsov New aspect of intercultural communication discourse modeling in the context of globalization and migration. Opción, 34, 85, 789-800 (2018)

12. Tao Yuan Teaching Chinese student's compatibility in translation from Chinese to Russian based on the corpus. Modern Humanities research, 2(63), 83-87 (2015)

13. D. Nakisbaev, N. Dubinina, I. Karabulatova, A. Levshits, L. Krivoshlykova Actual ethnopsycholinguistic methods of foreign languages teaching in higher education. Man in India, (23), 389-396 (2017)

14. I. S. Karabulatova, P. V. Barsukov, I. V. Akhmetov, O. V. Mamatelashvili, F. F. Khizbullin "Network Wars" as a New Type of Devitiaon Processes in the Modern Electronic and Information Society in the Context of Social and Economic Security. MJSS, 6, 6, S.3, 150-159 (2015)

15. E. R. Aitkulov Linguopragmatics of texts in the Internet space: based on the material of mass media of the Republic of Bashkortostan: abstract of the candidate of philological Sciences dis....: 10.02.20. Ufa, 23. (2017) (in Russ.)

16. S. Pozdyaeva, E. Ermakova, G. Shiganova, I. Karabulatova, R. Absalyamova, K. Kotik The Specificity of the Social-Publicistic Discourse of Soft Power in Modern Foreign Politics of China. Man in India, 97 (23), 517-524 (2017) //16

17. D. Kahneman Think slowly. Solve quickly. M.: AST, 653 (2016) (in Russ.)

18. L. Levi-Bruhl Supernatural in primitive thinking, Moscow: Pedagogika-Press, 608 (1994) (in Russ.)

19. I. S. Karabulatova Modern electronic information discourse as an indicator of ethnopolitical security: interethnic tolerance vs ethnoconflictogenicity in the XXI century. Scientific review. Series 2: Humanities, 2, 3-14 (2016) (in Russ.) 
20. T. B. Balaganova Ethnocultural features of mental disorders in Buryats. Diss. Cand.med.N. Novosibirsk: the ngma, 104 (2006) (in Russ.)

21. N. N. Zarubina Historical memory as a source of knowledge about the civilizational specifics of Russia. Social Sciences and modernity. 2, 52-63 (2017) (in Russ.) //21

22. Daria A little humor. Chinese signs a La Rus, from 16.07.2019. URL: https://zen.yandex.ru/media/id/5cf6688f2d133400afd9a0b5/nemnogo-iumorakitaiskie-vyveski-alia-rus-5d2dc6d746f4ff00ad7c495a?utm_source=serp (in Russ.)

23. . V. Kolomenskaya Russian advertising: on the issue of language specifics (based on Russian signage in Heihe, China). Word: folklore and dialectological almanac, 8, 3137 (2010) (in Russ.)

24. E. A. Oglezova The Russian Chinese pidgin: sociolinguistic experience of the description. Blagoveshchensk: Amur state University, 264 (2007) (in Russ.) //24

25. Lou Tintin Political linguistics in China: theory and main directions. Political linguistics, 5 (59), 46-55 (2016)

26. I. S. Karabulatova, Polivara Z. V. (2012). To the concept ethnopsycholinguistics norms in bilingual children. Special education, 1, 22-29 (2012) (in Russ.) 